\title{
A alocação de recursos para o tratamento medicamentoso oncológico no Sistema Único de Saúde - SUS
}

Recebido: 5 out. 2020 Aceito: 21 out. 2020

Autor de correspondência: Natalie Anceschi natalie.anceschi@yahoo.com.br

Conflito de interesses: Os autores declaram não haver nenhum interesse profissional ou pessoal que possa gerar conflito de interesses em relação a este manuscrito.

\author{
Natalie ANCESCHI: Faculdade de Saúde Pública - FSP, Universidade de São Paulo - USP. ORCID: \\ https://orcid.org/0000-0002-9135-2946 \\ Lúcia Dias da Silva GUERRA: Centro Universitário Anhanguera/campus Santana. ORCID: \\ https://orcid.org/0000-0003-0093-2687
}

\section{Resumo}

O câncer é o principal problema de saúde pública no mundo e já está entre as quatro principais causas de morte prematura, antes dos 70 anos de idade, na maioria dos países. A incidência e a mortalidade por câncer vêm aumentando no mundo, em parte pelo envelhecimento, pelo crescimento populacional, como também pela mudança na distribuição e na prevalência dos fatores de risco de câncer, especialmente aos associados ao desenvolvimento socioeconômico. A estimativa para cada ano do triênio 2020-2022 aponta que ocorrerão 625 mil casos novos de câncer no Brasil. O cálculo global corrigido para o sub-registro aponta a ocorrência de 685 mil casos novos. De acordo com a Portaria $n^{\circ}$ 2.439, de dezembro de 2005, documento pelo qual foi instituída a Política Nacional de Atenção Oncológica, a alta complexidade é apontada como componente fundamental desta última. Apresenta como atribuições: garantir acesso de pacientes com diagnóstico clínico ou histopatológico de câncer a esse nível de atenção, realizar estadiamento, prover tratamento e cuidado, e assegurar qualidade conforme rotinas estabelecidas. Embora a Portaria $n^{\circ} 2.439$ tenha sido revogada em favor da Portaria $n^{\circ} 874$, de maio de 2013, que implementou a Política Nacional para a Prevenção e Controle do Câncer na Rede de Atenção à Saúde das Pessoas com Doenças Crônicas no âmbito do Sistema Único de Saúde (SUS), as obrigações dos estabelecimentos de alta complexidade permanecem semelhantes. Segundo a Política Nacional para a Prevenção e Controle do Câncer, a atenção farmacêutica deve estar organizada para atender às necessidades do tratamento oncológico, de acordo com o plano regional de organização das linhas de cuidado dos diversos tipos de câncer, e com as regras de incorporação de tecnologias no SUS. Os medicamentos oncológicos representam o maior item de dispêndio do SUS com medicamentos. A forma pela qual é realizada atualmente a Assistência Farmacêutica oncológica no SUS não se ajusta adequadamente ao conjunto de medidas instituídas pelo Componente Especializado da Assistência Farmacêutica, na medida em que remunera os medicamentos em conjunto com outros itens do cuidado prestado ao paciente oncológico. O financiamento de medicamentos oncológicos não se dá por meio dos Componentes da Assistência Farmacêutica. Há uma política pública específica estruturada que preconiza o fornecimento do medicamento por meio do serviço habilitado em oncologia, a que o paciente está vinculado. O Ministério da Saúde e as Secretarias Municipais e Estaduais de Saúde não disponibilizam diretamente medicamentos contra o câncer. Os hospitais habilitados em Oncologia pelo SUS, sejam eles públicos ou privados, com ou sem fins lucrativos, são os responsáveis pelo fornecimento dos medicamentos para tratamento do câncer por meio da sua inclusão nos procedimentos quimioterápicos registrados no subsistema APAC-SIA (Autorização de Procedimento de Alta Complexidade do Sistema de 
Informação Ambulatorial) do SUS e são ressarcidos pelo Ministério da Saúde conforme o código da APAC. Estes medicamentos são padronizados, adquiridos e prescritos pelo próprio hospital e devem seguir os protocolos e diretrizes terapêuticas do Ministério da Saúde, quando existentes. Maior clareza sobre como é feita a alocação de recursos para o tratamento medicamentoso oncológico no SUS é necessária para compreender se o sistema está estruturado de forma coerente com o cenário atual. Diante disso, este trabalho tem por objetivo analisar as evidências disponíveis na literatura científica sobre a alocação de recursos para o tratamento oncológico no SUS. Este estudo é uma revisão da literatura do tipo integrativa que foi desenvolvida a partir da seleção sistemática da literatura científica, que possibilita um aprofundamento na compreensão de um determinado fenômeno com base em estudos anteriores, a construção de uma análise sobre as abordagens metodológicas e atualização dos resultados de pesquisas, além de reflexões sobre a realização de futuros estudos e a tomada de decisões com relação a intervenções. Para construção e desenvolvimento das etapas da revisão, foi realizada inicialmente a definição da pergunta norteadora: Como é feita a alocação de recursos para o tratamento oncológico no Sistema Único de Saúde (SUS)? e alguns dos critérios de inclusão, apresentados a seguir: a) tipo de documento - artigos científicos e b) idioma - português, inglês e espanhol. As bases de dados selecionadas foram BVS (Lilacs), Scielo, Pubmed (Medline), Scopus e Web of Science; e os termos primários de busca foram alocação de recursos, sistema único de saúde, oncologia e tratamento. A pergunta de pesquisa foi decomposta nos seguintes termos gerais de busca para a construção da expressão de busca (sintaxe): alocação de recursos (fenômeno), sistema único de saúde (contexto), oncologia e tratamento (objeto). Em seguida, realizou-se um mapeamento dos descritores e dos sinônimos utilizados nos DeCS (Descritores em Ciências da Saúde da Biblioteca Virtual em Saúde - BVS) para a identificação da terminologia padronizada. Foram realizados pré-testes da expressão de busca nas bases de dados, com a utilização dos operadores booleanos: $A N D, O R$, até chegar à versão final da expressão de busca que capturasse nas bases de dados o maior número de artigos de interesse do projeto. Após a realização da busca nas bases de dados, 117 registros foram encontrados, sendo 41 duplicatas excluídas. Para a revisão das publicações exportadas das bases utilizou o gerenciador de referências, Zotero. Depois foi organizada uma planilha em Excel para a revisão dos títulos e resumos. Por meio da leitura de títulos e resumos, permaneceram na revisão 20 artigos científicos para realização de leitura na íntegra e análise reflexiva. Espera-se com essa revisão compreender como é feita a alocação de recursos para o tratamento oncológico no Sistema Único de Saúde.

Descritores: Alocação de Recursos; Sistema Único de Saúde; Oncologia; Financiamento da Assistência à Saúde.

Keywords: Resource Allocation; Unified Health System; Medical Oncology; Healthcare Financing. Palabras-claves: Asignación de Recursos; Sistema Único de Salud; Oncología Médica; Financiación de la Atención de la Salud. 